\title{
Analysis of tungsten in low grade ores and geological samples
}

\author{
S C SRIVASTAVA, S R BHAISARE, D N WAGH* and C P S IYER** \\ Indian Bureau of Mines. Nagpur 440001, India \\ *Analytical Chemistry Division. Bhabha Atomic Research Centre, Bombay 400085, India \\ ${ }^{* *}$ Centre for Marine Analytical Reference and Standards, Regional Research Laboratory, \\ Trivandrum 695019 , India
}

\begin{abstract}
The determination of tungsten in low grade ores and geological samples is one of the most difficult and challenging tasks. Many of the associated elements, especially molybdenum interfere. These have to be overcome by suitable methods of separation or suppression of the interfering elements. Since the concentrations are low, instrumental methods are preferred over the classical methods. Thus spectrophotometry, fluorometry, atomic absorption spectrometry, atomic emission spectrometry. X-ray fluorescence, neutron activation analysis, electro analytical methods and chromatography are preferred. These are discussed in this review.
\end{abstract}

Keywords. Tungsten separation and determination; spectrophotometry; fluorometry; AAS: AES: XRF; NAA; electroanalytical; chromatography.

\section{Occurrence of tungsten}

Tungsten is commonly associated in nature with iron, manganese, calcium and to a limited extent with copper. The important minerals of tungsten are wolframite ( $\mathrm{Fe}$, $\left.\mathrm{MnWO}_{4}\right)$, scheelite $(\mathrm{CaWO})$, ferberite $\left(\mathrm{FeWO}_{4}\right)$, hubnerite $\left(\mathrm{MnWO}_{4}\right)$ and cupro scheelite $\left(\mathrm{Ca}, \mathrm{Cu}\left[\mathrm{WO}_{4}\right]\right)$. These minerals occur as fine disseminations in the parent rocks.

\section{Decomposition and dissolution}

In dissolving samples of silicate matrix in $\mathrm{HCl}$, tungsten in fine inclusions is left unattacked. Dissolution of the sample has to be done either in mixed acids $(\mathrm{HCl}-$ $\mathrm{H}_{3} \mathrm{PO}_{4}-\mathrm{HF}$ ) or with pyro sulphate fusion. The minerals, hubnerite and scheelite, are decomposed in acids. Wolframite and ferberite are resistant to the acid attack and about 0.3 to $0.5 \%$ of tungsten remains unattacked. Prolonged digestion on a hot plate until evaporation to a pasty syrup and dissolution in $2 \mathrm{~N} \mathrm{HCl}$ are recommended. Alternatively, fusion with potassium pyro-sulphate and extracting in $5 \mathrm{M}$ tartaric acid can be used. After dissolution of the sample, different methods of analysis are adopted depending on the type of sample and the associated matrix.

\section{Methods of analysis}

For the analysis of tungsten in low grade ores, the instrumental techniques of spectrophotometry, fluorometry, atomic absorption spectrometry, atomic emission spectrometry, X-ray fluorescence spectrometry, neutron activation analysis, electro analytical and chromatographic methods can be applied. A monograph on the methods of analysis of tungsten has been prepared by Ewell and Wood (1971). Reviews 
on the subject have been published by Chernikov and Goryushina (1946), Bagshawe (1954), Busev et al (1962), Chalmers (1962), Topping (1978) and Quin (1988).

\subsection{Spectrophotometry and fluorometry}

A number of chromogenic reagents for the spectrophotometric determination of small amounts of tungsten are described in the literature. All of them are prone to interferences by other elements as molybdenum, tin, antimony, niobium, etc. Among the reagents, thiocyanate and dithiol are widely used for the determination of small amounts of tungsten present in low grade ores and geological samples.

\subsection{Thiocyanate method}

Grimaldi and North (1943), were the first to suggest the determination of tungsten in rocks by dissolution in acids, reduction and formation of a soluble colour complex with thiocyanate. Sandell (1950) described in detail a method for the quantitative determination of tungsten in low grade ores. Freund et al (1951) reviewed the effect of the concentration of free acid, chloride and chlorostannous ion on the formation of the thiocyanate complex and recommended the optimum conditions. The same authors and earlier Geld and Carroll (1949), suggested the reduction of tungsten(VI) with stannous chloride at an elevated temperature, either by boiling or by placing the solution in a boiling waterbath. They have inferred that the interference of molybdenum in the determination of tungsten by thiocyanate is dependent not only on the amount of molybdenum but also on that of iron present in the sample solution. Crouthamel and Johnson (1954) used successfully solutions, $8 \mathrm{M}$ with respect to chloride and $10 \mathrm{M}$ with respect to acid and $0.5 \mathrm{M}$ of thiocyanate. Fogg et al (1970) made an exhaustive review of the thiocyanate method. It is stated that the main advantage of this method is the non-interference of $\mathrm{V}(\mathrm{V})$ and the higher tolerance limit of $\mathrm{Mo}(\mathrm{VI})$. Li and $\mathrm{Xu}$ (1987) determined tungsten in rocks by measuring the absorbance at $640 \mathrm{~nm}$ $\left(E=3.5 \times 10^{4} 1 \mathrm{~mol}^{-1} \mathrm{~cm}^{-1}\right)$ of the complex formed in $0.08-0.2 \mathrm{M} \mathrm{H}_{2} \mathrm{SO}_{4}$ with $12 \%$ $\mathrm{KSCN}$ and $0.05 \%$ Malachite green in presence of polyvinyl alcohol.

\subsection{Dithiol method}

Tungsten (VI) forms a bluish green complex with toluene 3,4-dithiol which can be extracted into solvents as butyl acetate. Miller (1944) reported that the interference of iron, copper, arsenic, gold and tellurium is eliminated by the addition of stannous chloride. Bickford et al (1948) and Allen and Hamilton (1952) mention that copper, bismuth, mercury and silver can be removed by extraction of their dithiozonates in carbon tetrachloride at $\mathrm{pH} 3$; molybdenum is subsequently removed as the dithiolate from cold $8 \mathrm{~N}$ sulphuric acid and tungsten is extracted as dithiolate in the $\mathrm{pH}$ range of $0.5-2 \cdot 0$. It is reported that the presence of phosphoric acid helps in the quantitative recovery of tungsten, possibly due to the formation of phospho tungstic acid species. Similarly the presence of iron, titanium, vanadium and zirconium speeds up the reaction between tungsten and dithiol. Short (1951) and Greenberg (1957) have described the extraction of tungsten as dithiolate from a warm strong hydrochloric acid 
solution containing stannous chloride with a prior separation of molybdenum as dithiolate from a 1:1 hydrochloric acid solution. Bagshawe and Trumen (1956) overcame the interference of Mo by selectively extracting it from a $4 \mathrm{M}$ acid solution, before extraction of $\mathrm{W}$. Extraction of the dithiol complex in heptane and subsequent measurement at $630 \mathrm{~nm}$ has been demonstrated by Welsch (1983). Yoshikuni (1984) extracted the complex in butyl phosphate-butyl acetate and measured the absorbance at $615 \mathrm{~nm}$. Murthy et al (1983) and Iyer et al (1987) studied the dithiol complex which is extracted into $n$-butyl acetate. Fan (1993) proposed a method of digestion of samples with $\mathrm{HF}-\mathrm{HNO}_{3}-\mathrm{HClO}_{4}$, extraction of $\mathrm{W}$ as the $\mathrm{x}$-benzoin oximate and determination as the dithiol complex. A sequential method of determination of $\mathrm{Mo}$ and $\mathrm{W}$ in silicate rocks has been proposed by Zhen (1992). Mo is extracted as dithiolate into $\mathrm{CCl}_{4}$ initially followed by tungsten. It is claimed that tungsten can be determined at parts per million level with relative standard derivation of $3.5 \%$.

\subsection{Other spectrophotometric methods}

Pashchonko et al (1974) compared the spectrophotometric methods using thiocyanate, salicyl-fluorone and catechol violet. Amongst them, salicyl-fluorone is found to be the most sensitive, but is prone to interferences. Golubstova and Labedeva (1974) preferred catechol violet, in the presence of molybdenum. Xin (1983) studied the ternary complex of tungsten with bromopyrogallol and cetyltrimethyl ammonium bromide. Wu et al (1985) describe a method of determining tungsten by complexation with salicylfuorone in presence of the surfactant, cetyl trimethyl ammonium bromide. The same surfactant has been used by Ma et al (1991) for the colour reaction of tungsten with antipyrineazopyrogallol (AnAp). The orange coloured complex having the molar ratio of W:AnAp as $1: 2$, has an absorption maxima at $475 \mathrm{~nm}$ with molar absorptivity of $6.44 \times 10^{4} 1 \mathrm{~mol}^{-1} \mathrm{~cm}^{-1}$. Beer's law is obeyed in the concentration range of $0-65 \mu \mathrm{g} / 25 \mathrm{ml}$. The method is applied to the spectrophotometric determination of tungsten in the tailing fractions of ores. Guo (1987) reported a method of determination of $\mathrm{W}$ in copper ores, by reaction with $o$-nitrophenyl fluorone and an emulsifying agent, op. Absorbance is measured at $510 \mathrm{~nm}\left(E=1.3 \times 10^{4} 1 \mathrm{~mol}^{-1} \mathrm{~cm}^{-1}\right)$. Reaction between W(VI) and 2,3,7-tri-hydroxy fluorone in the presence of cationic and nonionic surfactants has been studied for the spectrophotometric determination of tungsten by Nazarenko et al (1989). Luo and Wu Yanping (1989) determined tungsten in its ores based on the complex formed with $o$-chlorophenyl fluorone and cetyltrimethyl ammonium bromide in presence of nitrilo tri acetic acid. The absorption maxima occurs at $512 \mathrm{~nm}$ and Beer's law is obeyed in the tungsten concentration range of $5-25 \mu \mathrm{g} \mathrm{W} / 25 \mathrm{ml}$.

\subsection{Separation followed by spectrophotometry}

To overcome the interferences of other colour forming elements associated with tungsten, separation methods are employed. As mentioned earlier, solvent extraction has been used, for the separation of $\mathrm{W}$ as dithiolate. In the case of $\mathrm{W}$ thiocyanate also, it can be extracted with amyl acetate, $n$-amyl alcohol, butyl acetate cyclohexanol, ethyl acetate, ethyl ether, isopropylether and tributylphosphate. Isopropylether has got an edge over others, as it gives better phase separation. Dasler and Bauer (1946) and 
Hamstead et al (1961) recommended the purification of the organic solvents used for the extraction of tungsten-thiocyanate complex to eliminate organic peroxides, which prevent distinct separation of the phases. Extraction of W(VI) from $1 \mathrm{M} \mathrm{HCl}$ with $12 \mathrm{M}$ lithium chloride (as salting agent) into mesityl oxide has been carried out by Shinde and Khopkar (1969). On the other hand, ethylacetate has been chosen as an extractant by Fleury and Hubert (1971). A good number of techniques for the isolation of tungsten are reported by Yatirajam and Ram (1973). Jackson and Gleason (1973) used acetylacetone derivatives for tungsten extraction. The use of amines as extractants is described by Tseryata et al (1973) and Shiralieva and Verdizade (1984). Mishra et al (1990) proposed extraction of the thiocyanate complex with $3 \%$ thioacetanilide in benzene. The method has been applied, among others, to the determination of $W$ in ores. It is reported that the results are comparable to the standard thiocyanate method. Andreeva et al (1985) determined W(VI) by extracting its $1: 2: 2$ complex, with bromopyrogallol red and cetylpyridinium into chloroform from $1 \mathrm{M} \mathrm{HCl}$ and measuring the absorbance at $600 \mathrm{~nm}$. Mov Sumov et al (1988) studied the complexation of tungsten with hydroxy thiophenols and subsequent extraction of the complex in $\mathrm{CCl}_{4}$. The absorption maxima of the complex is reported to be $440-480 \mathrm{~nm}$. Yuan (1989) found that amines are excellent extractants for tungsten in the sequence of quarternary amine $>$ tertiary amine $>$ secondary amine $>$ primary amine.

In addition to separation of the $\mathrm{W}$ complex by solvent extraction, other separation methods are also employed. A simple procedure of separation of $\mathrm{W}$ as the thiocyanate complex on polyurethane foam sorbent, elution with acidified acetone and subsequent spectrophotometric determination has been proposed by Ray Choudhary et al (1992) for analysis of tungsten in silicate rocks. $\mathrm{Co}(50 \mu \mathrm{g} / \mathrm{ml}), \mathrm{Cu}(10 \mu \mathrm{g} / \mathrm{ml}), \operatorname{Ti}(20 \mu \mathrm{g} / \mathrm{ml})$, $\mathrm{V}(10 \mu \mathrm{g} / \mathrm{ml})$ and $\mathrm{Mo}(0.5 \mu \mathrm{g} / \mathrm{ml})$ can be tolerated for tungsten in the range of 0.1 $12 \mu \mathrm{g} / \mathrm{ml}$. Spectrophotometric determination of tungsten in rocks after selective absorption on sephadex gel column from acid solution at $\mathrm{pH} 2.5$ and desorption with EDTA solution has been described by Hase et al (1985). Pyrogallol red has been used for the colour development, the absorbance being measured at $576 \mathrm{~nm}$. Tungsten in rock samples up to $1 \mathrm{mg} / \mathrm{kg}$ can be determined by this method. Separation and concentration of W(VI) with chelation ion exchange resin containing sulphur ligands have been reported by Liu and Sun (1984). W(VI) can be selectively sorbed on a short column of thioglycolic acid resin from pH $4 \cdot 3$ acetate buffer and eluted with $0 \cdot 1 \mathrm{M}$ $\mathrm{NaCl}$. Liu and Wen (1990) separated W on a column of GDX-103 resin coated with TOPO-xylene and determined it spectrophotometrically with salicyl fluorone and hexadecyl trimethyl ammonium bromide. Alumina has been used by Klofutar et al (1970) and Gladney (1978) to separate W. Yunikova and Boichinova (1984) separated W by adsorption on zirconia and elution with $\mathrm{NaOH}$. Gaibakyan and Sarikisyan (1991) studied the separation of $W$ on paper and on alumina, from a medium containing salicylic acid, sulfo salicylic acid or thio salicylic acid. Tremenendzhyan and Gaibakyan (1974) used electrochromatography to separate W from a $0 \cdot 1 \mathrm{~N}$ potassium tartarate solution.

\subsection{Fluorometry}

Reagents forming fluorescent compounds with tungsten are few in number. The fluorometric reagent, 3-hydroxyflavone, used in the fluorometric determination of 
tungsten has been reviewed by Nevskaya and Nazarenko (1972). Fluorometric determination of tungsten with morin, which forms a $1: 1$ complex with W(VI) at pH 5.5 has been reported by Pilipenko et al (1974). Fluorescent complexes with carminic acid at pH $5 \cdot 1$ is reported by Salinas et al (1989) for the determination of W.

\subsection{Atomic absorption spectrometry $(A A S)$}

The application of atomic absorption spectrometry (AAS) in the analysis of tungsten is limited, due to poor sensitivity. The element forms refractory oxides in the flame, which is unsuitable in AAS analysis. The use of nitrous oxide-acetylene flame or graphite furnace with the application of preconcentration techniques, have improved the situation. Keller and Parsons (1970) demonstrated the possibility of analysis of tungsten in silicate ores by atomic absorption spectrometry. Rao (1970) reported on determination of $\mathrm{W}$ in ores. The sample is fused with lithium tetraborate, extracted with phosphoric acid and methyl-tricarpyl ammonium chloride in 2,6-dimethyl-heptan-2one and analysed by AAS using nitrous oxide-acetylene flame. Thomas and Pickering (1971) studied the effect of solution equilibria on the atomic absorption intensity signal. Morrow (1972) determined tungsten by AAS after extracting it as tungsten-toluene3,4-dithiol complex into butyl acetate. Raoot et al (1987) determined tungsten in ores and alloys by AAS at $400.9 \mathrm{~nm}$ using nitrous oxide-acetylene flame. Ganguly et al (1987) have used AAS, after fusing the sample with $\mathrm{KHSO}_{4}$ and extracting the fused mass in ammoniacal citrate solution. The interference of manganese and the depressing effect of calcium have been eliminated by the addition of titanium. Tungsten in silicate ores has been determined by Rao et al (1987) by dissolving the sample in $\mathrm{HF}-\mathrm{HCl}-$ $\mathrm{H}_{3} \mathrm{PO}_{4}$ acids and enhancing the tungsten absorption signal by the addition of aluminium. The resonance line selected for the measurement is $255.1 \mathrm{~nm}$. A method for the determination of tungsten in wolframite, scheelite and cassiterite by AAS, has been described by Chong and Meriam (1987). Potassium hydrogen sulphate has been used as an effective flux and also as a powerful enhancing and releasing agent. Addition of sodium silicate solution has been demonstrated to suppress the calcium interference. Abbasi (1989) determined tungsten, after extraction of W(VI) from $2-8 \mathrm{M} \mathrm{HCl}$ or 15-20 $\mathrm{M} \mathrm{H}_{2} \mathrm{SO}_{4}$ medium with $N$-P-methoxyphenyl-2-furylacrylo hydroxamic acid (MFHA) in MIBK and measuring the absorption at $400.9 \mathrm{~nm}$, employing nitrous oxide-acetylene flame. Malhotra and Murthy (1987) determined tungsten in scheelite or wolframite by fusing with $\mathrm{KHSO}_{4}$, taking in citric acid, adjusting the $\mathrm{pH}$ to 7-8, and adding of Ti as modifier. Iyer and Pillai (1990) directly determined tungsten in ores by AAS, with nitrous oxide-acetylene flame by decomposing the sample with HF-aqua regia, making the final solution in $\mathrm{HF}-\mathrm{HClO}_{4}$. Calibration range was $100-600 \mu \mathrm{g} / \mathrm{ml}$ and measurements were carried out at $255.1 \mathrm{~nm}$. In contrast to the above mentioned method of direct determination, separation of tungsten, on a silica column, followed by its determination on AAS using nitrous oxide-acetylene flame has been reported by Kirkbright and Sargent (1974).

\subsection{Atomic emission spectrometry}

Ivanova (1966) and Kuznetsov and Raikbaum (1967) reported the determination of $\mathrm{W}$ in rocks, using AES. The tungsten lines recommended are 400.88, 429.46 and 
$430.21 \mathrm{~nm}$. Other lines such as 289.65 and $294.70 \mathrm{~nm}$ are also available. The major problem is the poor intensity of the emission. Various workers have attempted to overcome this drawback. Thus addition of silica, sulphur or germanium oxide have been used to improve the intensity of the emission lines of tungsten. It is also reported that, the presence of various halides as silver chloride, phosphorus penta chloride, helps in the formation of more volatile species of tungsten, resulting in improved emission. These have been summarized by Kolthoff et al (1978). Subsequently, Kuznetsov and Afonina (1987) have reported that the addition of natural antimonite in the analysis of rocks, lowers the detection limits to $0.5 \mathrm{ppm} \mathrm{W.} \mathrm{Lin} \mathrm{and} \mathrm{Mao} \mathrm{(1987)} \mathrm{analysed} \mathrm{tungsten}$ in geochemical samples, after addition of $\mathrm{CdCl}_{2}$. Chen (1988) reviewed the methods of improving the detection limit of tungsten, by the methods of chlorination and sulphuration.

With the advent of plasma as an excitation source, there has been a marked improvement in the analysis of $\mathrm{W}$ by AES. Plasma emission spectroscopy has been applied in tungsten analysis with higher sensitivity by Wunsch (1979) and Czech and Wunsch (1981). The application of ICP-AES for the determination of tungsten in geological material is described by Thompson and Walsh (1983). Raoot et al (1987) determined tungsten in the concentration range of 0.002 to $0.8 \%$ by direct current plasma emission spectrometry using the tungsten emission line at $400.87 \mathrm{~nm}$. Markova and Petrokova (1987) investigated in detail potentially interfering matrix elements on the determination of tungsten in ores by ICP-AES and have suggested a method of background correction. Fusion of sample with $\mathrm{NaOH}$, analysis by ICP-AES at $220.4 \mathrm{~nm}$, has been proposed by Bhattacharjee (1992). Tang et al (1991) extracted tungsten as the thiocyanate into isobutyl methyl ketone, before determination by ICP-AES. Recoveries from geochemical samples were in the range of 90 to $100 \%$. Detection limit of $0.05 \mu \mathrm{g} \mathrm{W} / \mathrm{ml}$ is reported. Hall et al (1987) described a method of determination of tungsten in the concentration range of $0.5-100 \mu \mathrm{g} / \mathrm{g}$ level in geological materials by ICP-AES. A detection limit of $0.4 \mu \mathrm{g} / \mathrm{g}$ has been reported. Hall et al (1987) also used ICP-MS, for the determination of $\mathrm{W}$ in geological materials. Rhenium is used as internal standard. A detection limit of $0.07 \mu \mathrm{g} / \mathrm{g} \mathrm{W}$ is reported.

\subsection{X-ray fluorescence spectrometry}

$\mathrm{X}$-ray fluorescence spectrometry (XRF) is a rapid, accurate and nondestructive, multielement analytical technique for the qualitative and quantitative analysis of elements in a variety of materials. The work of Pantony and Hurley (1972) and Giaque et al (1977) may be referred for the tungsten analysis by XRF. Compared with the other techniques, the determination of tungsten by XRF has proved popular. There are possible interferences from the $0.1476 \mathrm{~nm} \mathrm{~L}$ line of $\mathrm{Yb}(2 \mathrm{ppm} Y \mathrm{Yb}=1 \mathrm{ppm} \mathrm{W})$. Alternatively the $0.0211 \mathrm{~nm} \mathrm{~W} \mathrm{~K}$ line can be used, but the poor signal to background ratio result in unsatisfactory detection limits. Different tungsten minerals give different intensities which is a persistent problem in tungsten analysis. About $20 \%$ difference in W L line intensity per unit concentration is observed when the sample matrix changes from scheelite to wolframite. It is suggested to use fused glass discs of sample to eliminate this problem. Srivastava et al (1980) and Rajeev et al (1980) suggested that the matrix effects can be minimized by selecting standards of the same origin having similar mineralogical composition as that of the samples to be analysed. Chen and Fu (1984) 
determined $\mathrm{W}$ in ores by using XRF. The sample is decomposed with sodium peroxide and the melt is leached with citric acid solution. The complex thus formed is acidified with phosphoric acid and the intensity measurements are done. Scattered radiation is used as internal standard. Chen (1985) determined tungsten in tungsten minerals and ores by XRF. The sample is fused with lithium tetraborate and bromide at $1050^{\circ}-1100^{\circ}$ in a $\mathrm{Pt}-\mathrm{Au}$ crucible. Barium nitrate is added to the fusion mixture to act as a heavy absorber. An oxidizing atmosphere is maintained during the early stage of fusion. Tantalum is used as an internal standard. The accuracy and precision has been claimed to be as good as that of classical chemical methods. A method using XRF for the determination of $\mathrm{W}$ after separation on an ion exchange resin is described by Eddy and Balaes (1985). The dried resin is milled with sand, binder and internal standard mixture of $\mathrm{Nb}$ and $\mathrm{Zn}$. Intensity measurements are made with gold $\mathrm{X}$-ray tube as source.

Application of some correction algorithms in XRF analysis of tungsten in low grade wolframite has been demonstrated by Rajeev (1986). Tungsten analysis, methods, problems and their corrective measures have been discussed by Srivastava and Singh (1987). Direct determination of tungsten in a tungsten ore beneficiation process by XRF has been demonstrated by Ding (1989). Samples are prepared by pelletizing the sample powder with low density polyethylene, as binding material. Scattered lines have been used as internal standard and matrix corrections are made by the empirical coefficient method. A comparative study of classical chemical methods and XRF after fusing with lithium tetraborate has been described by Garcia et al (1989).

Determination of tungsten in low grade ores by energy dispersive X-ray fluorescence has been described by Chacharkar et al (1987). A minimum detection limit of $33 \mathrm{ppm}$ is reported. Sen et al (1989) separated tungsten by extraction with $n$-phenyl hydroxamic acid in toluene after dissolution of rock and mineral samples in $\mathrm{H}_{2} \mathrm{SO}_{4}$. The organic extract was collected on cellulose powder, dried and pressed into a disc for XRF. Limit of detection is $10 \mathrm{ppm}$.

Development of portable X-ray spectrometer based on X-ray excitation by a radioactive source has been described by Gallagher (1970). The theory and application of this technique has been presented by Chan and Jones (1972) and Kussi et al (1972). Wenk and Wilkinson (1974) and Zaitsev et al (1974) applied this technique for the rapid determination of tungsten in ores and geological samples respectively. Hughes and Scholes (1972), Bochinin (1973), Ochkur et al (1973) and Karamanova and Bochvarov (1974) have mentioned that cobalt-57 and promethium-147 are satisfactory radioactive sources, for the determination of tungsten.

\subsection{Neutron activation analysis}

Neutron activation analysis (NAA) is found to be one of the most sensitive techniques for the determination of tungsten. It is non-destructive and has multi-elemental capability. Theoretically in this technique, the detection limits of an element can be improved by selecting the neutron flux and irradiative time.

Mc Clendon and DeVoe (1969), Baishya and Heslop (1971) and Nadkarni and Haldar (1971) described substoichiometric methods for the determination of tungsten. Radiochemical separations of tungsten by solvent extraction and ion exchange have been described by Bryne (1971) and Miklishanskii et al (1974). Iyer and Parthasarathy (1972) analysed ores of tungsten based on measurement of the radioactive isotopes 
${ }^{187} \mathrm{~W}$ (half life $24 \cdot 1 \mathrm{~h}$ ) produced by the irradiation of ${ }^{186} \mathrm{~W}$ with neutrons. The optimization of irradiation time, and cooling time required for the decay of short lived radioisotopes which may otherwise interfere with the measurement of ${ }^{187} \mathrm{~W}$ have been described.

A method employing NAA, described by Simon and Rollinsov (1975) is capable of detecting tungsten up to $0.005 \mu \mathrm{g} / \mathrm{g}$ with a relative standard deviation of $20 \%$. The procedure describes the extraction of tungsten as its complex with $\alpha$-benzoin oxime into chloroform prior to determination. The activity of the 0.13 and $0.48 \mathrm{MeV}$ gamma rays are measured and the yield determined by the measurement of the $0.155 \mathrm{MeV}$ gamma ray of ${ }^{188} \mathrm{Re}$ in equilibrium with ${ }^{188} \mathrm{~W}$, added prior to fusion of sample with peroxide. Randa et al (1970) and Tamura (1974) used NAA for the determination of tungsten in silicate rocks. In this procedure, the sample is irradiated by thermal neutrons for $1-4 \mathrm{~h}$, followed by peroxide fusion, rapid separation on alumina column before the measurement of activity. A detection limit of $15 \mathrm{ppm}$ of $\mathrm{W}$ in molybdenum ores is reported. Zinner et al (1972) used NAA for the determination of W in silicate rocks. Metelev et al (1991) used NAA, by irradiating the sample with thermal neutrons from $\mathrm{Cf}$ source for $24 \mathrm{~h}$. After cooling for $24 \mathrm{~h}$, the activity was measured with a Ge(Li) detector. Limit of detection was $50 \mathrm{ppm}$.

\subsection{Electro-analytical technique}

Many of the electroanalytical methods for tungsten are based on potentiometric titration. Tungsten forms an anionic complex with hydrogen peroxide which has been suitably utilized by Pyatnitskii and Chung (1969). Similarly they had in 1970, reported a potentiometric titration with sodium sulfite. Separate break points occur for free peroxide and peroxide complex of tungsten during the titration. Iron is masked with fluoride. Other ions forming peroxide complexes are separated before titration. Kuznetsov (1993) reported a high frequency titration with hydrogen peroxide, after addition of tetraborate to $\mathrm{W}$ in solution. A tungsten-calomel electrode pair has been employed by Geyer and Neumann (1969) in the titration of tungsten as $\mathrm{WO}_{4}^{2-}$ with standard lead nitrate solution. In a similar system, Mascini and Liberti (1972) used lead membrane ion selective electrode to sense the first excess of $\mathrm{Pb}^{2+}$ ion, at the end point of the titration. Potentiometric determination of tungsten by titration with standard potassium dichromate or amperometrically with standard potassium ferricyanide has been described by Kulev et al (1973). W(VI) is reduced to W(III) with tin and hydrochloric acid before titration. Amperometric determination of tungsten with standard solution of diantipyrinylmethane with a relative error of $<4.5 \%$ has been described by Lugovoi and Paklerova (1974). Mo(VI), V(V), As(V), $\mathrm{PO}^{4-}$ are reported to interfere in the titration. Dithiozone impregnated membrane electrode has been used by Lal (1971) in the titration of silver nitrate with $\mathrm{WO}_{4}^{-}$. Sinclair (1969) utilized a glass calomel electrode to follow the $\mathrm{pH}$ of tungsten--mannitol solution complex on titration with standard sulfuric acid. A break in the titration curve is reported when one proton has been added per tungsten ion. A wax impregnated carbon electrode has been used by Smith and Pope (1968) in the titration of W(VI) with standard chromous sulphate solution. Relative error of less than $1 \%$ is reported. Two titrimetric methods for the determination of tungsten have been described by Altun and Berkem (1984). In the first method, tungsten is reduced with $\mathrm{Zn}$ in $\mathrm{HCl}$ medium and then titrated with standard 
$\mathrm{KMnO}_{4}$. The second method is based on titration with $\mathrm{BaCl}_{2}, \mathrm{SrCl}_{2}$ or $\mathrm{CaCl}_{2}$ and detection of the end point by conductometric method. Tungsten(VI) in hydrochloric acid, exhibits a characteristic polarographic plateau which is utilized for its determination in ores. The finely ground ore sample is treated with conc $\mathrm{HNO}_{3}$, and the precipitated $\mathrm{WO}_{3}$ is leached with $\mathrm{HCl}$, to remove the interfering ions. Two reduction steps occur. The second reduction wave around $-0.4 \mathrm{~V} \mathrm{vs} \mathrm{Hg}$ pool electrode is used for determination of $\mathrm{W}$ in ores containing 0.001 to $0 \cdot 100 \% \mathrm{WO}_{3}$. The method involves the separation of $\mathrm{W}$ from matrix elements by extraction of the $\alpha$-benzoin oxime complex, from acidic solution into $\mathrm{CHCl}_{3}$. The organic extract is decomposed with $\mathrm{H}_{2} \mathrm{SO}_{4}$ $\mathrm{HNO}_{3}-\mathrm{HClO}_{4}$ mixture and the catalytic current is recorded in presence of $0.5 \mathrm{M}$ $\mathrm{NH}_{2} \mathrm{OH}$ and $0.002 \mathrm{M}$ of pyrocatechol at $\mathrm{pH} 3.0$. The method is capable of determining $\mathrm{W}$ at concentration of $10^{-4} \%$. Bhowas and Bhattacharya (1989) described a polarographic method of determination of tungsten after extracting W-salicyl-hydroxamate into methyl iso-butyl ketone or in a mixture of chloroform and iso-butyl alcohol from $1.5 \mathrm{M} \mathrm{HCl}$.

The catalytic activity of W has been utilized by various workers. Thus Xia et al (1991) reported a method for the determination of $W$ in geochemical samples based on the catalytic wave at $-1.22 \mathrm{~V}$ vs SCE of tungsten-salicylfluorone complex. Sun (1991) worked out a method for the determination of $\mathrm{W}$ in rocks. This is based on catalytic polarographic wave at $-0.78 \mathrm{~V}$ vs $\mathrm{SCE}$, of $\mathrm{W}$-benzilic acid-diphenyl guanidine complex in the presence of $\mathrm{NaClO}_{4}$. Peng and $\mathrm{Wu}(1988)$ determined $\mathrm{W}$ in geochemical samples by catalytic oscillopolarography of tungsten-cinchonine in presence of $\mathrm{KCl}$.

\subsection{Chromatographic methods}

Till very recently, chromatographic methods were not attempted for the analysis of tungsten. However, with vast improvements in the instrumentation of high pressure liquid chromatograph (HPLC) and ion chromatograph (IC), various workers have tried to take advantage of dual possibilities of separation and detection, of the above mentioned techniques.

Bol'shova et al (1988) separated $W$ as its chelate with quinoline-8-ol, using an HPLC column of Silesorb-600 and $\mathrm{CH}_{2} \mathrm{Cl}_{2}$-Propan-2-ol as the mobile phase. Detection was made spectrophotometrically at $254 \mathrm{~nm}$. Similarly, Ding (1993) separated W as its chelate with tetracycline on a HPLC nucleosil C-18 column with a mobile phase of acetonitrile-water containing citric acid and sodium chloride. Very similar to HPLC is ion chromatography except that the columns used are of ion exchange materials. In the case of $\mathrm{W}$, it can be converted to $\mathrm{WO}_{42-}$, which indicates the possibility of using anion exchange chromatography. Zolotov et al (1983) converted $\mathrm{W}$ into $\mathrm{WO}_{42}$ - with $\mathrm{H}_{2} \mathrm{O}_{2}$, loaded it on the column and used $5 \mathrm{mM} \mathrm{Na}_{2} \mathrm{CO}_{3}$, for eluting it from the column. Weiss et al (1988) used $1 \mathrm{mM} \mathrm{Na}{ }_{2} \mathrm{CO}_{3}$ in $2 \mathrm{mM}$ tetra butyl ammonium hydroxide-acetonitrile as the eluent. Mehra and Frankenberger (1989) analysed tungsten in soils and sludges using single column IC, with $o$-hydroxy benzoic acid, as the eluent. For the first time, Wagh (1990) reported the determination of $\mathrm{W}$ in low grade ores by chromatography. He used dual column IC and $8 \mathrm{mM} \mathrm{Na}_{2} \mathrm{CO}_{3}$ as eluent. Separation from other interfering elements as $\mathrm{Mo}, \mathrm{Cr}, \mathrm{V}$ could be successfully achieved. 


\section{The Indian scenario}

In India, the availability of large deposits of good tungsten ores is rather poor. The deposits which are being explored are the Degana mines (Rajasthan), Chanda Pathar (West Bengal), Agargaon and Sonegaon (Maharashtra), Burugubanda (Andhra Pradesh). Except Degana mines, the tungsten content in these ores is very low, i.e. of the order of 0.01 to $0 \cdot 10 \%$. In view of this and also because of the strategic importance of tungsten, it was necessary to develop analytical methods of high sensitivity so as to help exploration of tungsten. The work carried out by the Indian scientists, in this area, are mentioned in this text at appropriate places.

In this context, it is also appropriate to recall the contribution made by the Mineral Development Board, Govt. of India during the period from 1984 to 1987. An interlaboratory comparison of the analysis of seven batches of homogeneous low grade ores with varying tungsten contents from $0.02 \%$ to $0.80 \%$ was conducted by the Board. Six laboratories participated in the exercise. The analytical values varied widely especially for the lowest as well as for the highest tungsten contents of these ore samples. This was because the tungsten values were almost at the limit of detection for the sample containing $0.02 \% \mathrm{WO}_{3}$ where the errors could be serious. At the higher level of $0.80 \% \mathrm{WO}_{3}$ the errors were traced to the failure in bringing all the tungsten values in solution. Once the errors were identified and taken care of, there was better acceptability in results. It is reported that the values of $\mathrm{WO}_{3}$ in alluvial and phyllite samples, are more consistent due to the uniform small particle size. In Hutti scheelite the analytical figures for $\mathrm{WO}_{3}$ is more or less consistent as they are amenable to solution in contrast to wolframite.

Wagh (1990) carried out the determination of W in a few samples of low grade ores by different techniques of thiocyanate-spectrophotometry, ICP, XRF and NAA. The results by spectrophotometry, ICP and NAA, by and large, agreed with one another. In the case of XRF, the values were lower, which was attributed to the mismatch of the samples with the standards used for calibration.

\section{Conclusion}

As can be seen from the review, a number of analytical methods are available for the determination of tungsten. Among these XRF is the most popular technique especially when a large number of samples of similar type are to be analysed. Moreover, this does not involve bringing the sample in solution. Portable XRF units have proved extremely useful in the exploration stages where the determinations can be done in the field itself. The limitation of this technique is the necessity to have matching standards. Neutron. activation analysis is by far the most sensitive of all techniques, but limited in use due to constraints on the availability of nuclear reactors for irradiation purposes.

Atomic absorption technique has not been used to a large extent, due to poor sensitivity. Atomic emission especially with ICP is gaining ground with better instrumentation. Electroanalytical methods in spite of inherent sensitivity is still not widely practiced for the analysis of tungsten, as it calls for a good deal of analytical skill. Ion chromatography, though not as sensitive as spectrophotometry, is a technique, which should be given better consideration. Once the sample is brought into solution, there are no major steps involved prior to determination. It has the added advantage that the other ionic species present in the sample especially Mo, which is a major interference in some of the other methods, does not interfere and can also be determined. 
The spectrophotometric methods based on the thiocyanate and dithiol still continue to be popular. The methods are sensitive, precise and accurate. But it should be understood that to get meaningful results, especially where solution techniques are involved as in spectrophotometry, AAS, ICP and IC, all tungsten values have to be brought in solution. This is still an art of the experienced analytical chemist.

\section{Acknowledgement}

The authors acknowledge with thanks the help rendered by Shri S Karthikeyan, Shri S Chandaramouleeswaran. Dr M Anbu and Smt V S Lekha, RRL, Trivandrum and Shri Maneesh Singh, Tata Research Development and Design Centre, Pune in the preparation of the manuscript.

\section{References}

Abbasi S A 1989 Int. J. Enitiron. Anal. Chem. 35134

Allen and Hamilton 1952 Anal. Chum. Acta 7143

Altun E and Berkem A R 1984 Kim. Sanayi 27137

Andreeva I Yu, Lebedeva L C and Shabtina M Yu 1985 Fiz. Khim. 165

Bagshawe B J 1954 Chemical Age 70 267, 309

Bagshawe B J and Trumen R J 1956 Analyst 81104

Baisya N K and Heslop R B 1971 Anal. Chim. Acta 5387

Bhattacharjee S 1992 Spectrosc. Eur. 426

Bhowas S K and Bhattacharyya M 1989 Talanta 36989

Bickford C F. Jones W E and Keene J S 1948 J. Am. Pharm. Assoc. 8 T 255

Bochinin V I 1973 Zovodsk. Lab. 39135

Bol'shova A yu. Basova E M. Malykhim A yu and Poplavskaya E N 1988 Zh. Anal. Khim. 432229

Bryne A R 1971 Yugosl., At. Energy Comm. Rept. IJS-R-596

Busev A I, Tiptsova V G and Khlystou A D 1962 Zavodsk. Lab. 281414

Chacharkar M P. Sathe M D and Lal Madan 1987 J. Radiounal. Nucl. Chem. 11929

Chalmers R A 1962 Comprehensive analytical chemistry (eds) C L Wilson and D W Wilson (Amsterdam: Elsevier) vol. Ic

Chan F L and Jones W B 1972 Ad: X-ray Anal. 15209

Chen Maoqi and Fu Bin 1984 Fenxi Huarue 12384

Chen Pitong 1985 Fenxi Huaxue 13542

Chen S 1988 Yankuang Ashi 7152

Chernikov Y A and Goryushina V G 1946 Zatods Lab. 12517

Chong Chow and Meriam Nik 1987 Analyst 112627

Crouthamel C E and Johnson C E 1954 Anal. Chem. 261284

Czech N and Wunsch G 1981 Spectrochim. Acta B36 6

Dasler W and Bauer C D 1946 Ind. Eng. Chem. Anal. Ed. 1852

Ding Xuexin 1989 Australian J. Exp. Biol. Med. Sci. 25516

Ding Xuexin 1993 Talanta 40641

Eddy B T and Balaes A M E 1985 Spectrochim. Acta B40 1139

Ewell W T and Wood D F 1971 Analytical chemistry of molybdenum and tungsten (New York: Pergamon)

Fan Z H 1993 Anal. Chim. Acta 270267

Fleury A and Hubert F 1971 Bull. Soc. Chim. France 3090

Fogg A G, Marriot D R and Burns D T 1970 Analyst 95854

Freund H, Wright M L and Brookshier R K 1951 Anal. Chem. 23781

Gaibakyan D S and Sarikisyan Z V 1991 Zh. Anal. Khim. 291991

Gallagher M J 1970 Proc. 9th commonwealth min. metall conyress 19692691

Ganguly M K. Murty D S R and Malhotra R K 1987 Proc. of national workshop on tungsten resources detelopment, RRL (Bhubaneswar) and DMRL (Hyderabad) 3, 4 p. 139 
Garcia Garzon J, Martin Rubi J A and Garcia Frutos J 1989 An. Quim. Ser B. 85166 Geld I and Carroll J 1949 Anal. Chem. 211098

Geyer R and Neumann M 1969 Acta Chem. Acad. Sci. Hung. 60349

Giaque R D, Garrett R B and Goda L Y 1977 Anal. Chem. 491012

Gladney E S 1978 Anal. Lett. A11 429

Golubtsova Z G and Labedeva L I 1974 Vestn. Leningrad Univ. Fiz. Khim. 152

Greenberg P 1957 Anal. Chem. 29896

Grimaldi P S and North V 1943 Ind. Eng. Chem. Anal. Ed. 15625

Guo Z 1987 Fenxi Shyanshi 653

Hall G E M, Park Chang J and Pelchat J C 1987 J. Anal. At. Spectrometry 2189

Hall, Gwendy E M, Pelchat J C and de Silva K N 1987 Analyst 12631

Hamstead A C. Leis D G and Vanderlender L S 1961 Ind. Eng. Chem. 53 63A

Hase U, Yoshimura K and Tarutani T 1985 Anal. Chem. 571416

Hughes H and Scholes P H 1972 Br. Steel. Corp. open Rept., GS/Tech/V/6/72 C

Ivanova G F 1966 Geokhimiya 101206

Iyer C S P and Parthasarathy R 1972 Radiochem. Radioanal. Lett. 1212-3 201

Iyer N V, Krishanan R R V, Navale A S, Sivaramakrishnan K V and Murthy P S 1987 Proc. of national workshop on resources development, RRL (Bhubaneswar) and DMRL (Hyderabad)

Iyer S G and Pillai C K 1990 Indian J. Tech. 28113

Jackson W M and Gleason G 11973 Anal. Chem. 452125

Karamanova Z S and Bochvarov N V 1974 Isotopen Paraxis 10100

Keller E and Parsons M L 1970 Atomic Absorption News Letter 992

Kirkbright G F and Sargent M 1974 Atomic absorption and fluorescence spectroscopy (London, NY: Academic Press)

Klofutar C, Krasovec F and Kodre A 1970 J. Radioanal. Chem. 53

Kolthoff I M, Philip J Elving and Sandell E B 1978 Treatise on anal. chem. (New York: John Wiley \& Sons) Vol. 10

Kulev I, Gavanarov P and Staney D 1973 Rudodobiv. Met. Sofia 2828

Kussi J, Virtanam M and Jauho P 1972 Nucl. Technol. 13216

Kuznetsov A I and Afonina G G 1987 Zavod Lab 5330

Kuznetsov A I and Raikbaum Ya D 1967 Zavod Lab 331076

Kuznetsov V V 1993 Zh. Anal. Khim. 48117

Lal S 1971 Z. Anal. Chem. 255210

Li G and Xu Q 1987 Fenxi Shiyanshi 656

Lin C and Mao C 1987 Yankuang ceshi 6270

Lin C and Mao C 1988 Lihua Jiaxyan Huaxue Fence 24100

Liu Chuen Ying and Sun Peng Joung 1984 Talanta 31353

Liu S and Wen J 1990 Gaodeng Xuexiao Huaxue Xuebao 11355

Lugovoi S V and Paklerova L D 1974 Zh. Anal. Khim. 291748

Luo Zongming and Wu Yanping 1989 Huaxue Tongbao 642

Ma Wanpei and Zheng Peilin 1991 Fenxi Shiyanshi 91

Malhotra R K and Murthy D S R 1987 At. Spectrosc. 8161

Markova I S and Petrokova A 1987 Fresnus Z. Anal. Chem. 328239

Mascini M and Liberti A 1972 Anal. Chim. Acta 60435

Mc Clendon L T and De Voe J R 1969 Anal. Chim. 411454

Mehra H C and Frankenberger W T 1989 Anal. Chim. Acta 217389

Metelev A Yu, Ivanenko V V and Gud G M 1991 Zavod Lab 936

Miklishanskii A Z, Leikin Y A, Yakovlev Y V and Savelev B V 1974 Zh. Anal. Khim. 291284

Miller C C 1944 Analyst 69109

Mishra N, Ghosh A, Mishra R K and Patel K S 1990 Anal. Sci. 6407

Morrow R W 1972 Report of U.S. Atomic Energy Commission., Y-1812 11

Mov Sumov F M, Mamedov M M and Alekperov R A 1988 Azerb. Khim. Zh. 1104.

Murthy P S, Venkitakrishnan R R, Navale A S, Sivaramakrishnan K and Iyer N V 1983 Adv. Sci. Technol. 685

Nadkarni R A and Haldar B C 1971 J. Radioanal. Chem. 845

Nazarenko V A, Veshchikava N A, Novoselova M M, Antonovich V P, Anokhine N S and Suvorova E N 1989 Zh. Anal. Khim. 392151

Nevskaya E M and Nazarenko V A 1972 Zh. Anal. Khim. 271699 
Ochkur A P, Leman E P, Kotel'nikov V V, Ivanov M and Yanshevskii Y P 1973 At. Energ. 35204

Pantony D A and Hurley P W 1972 Analyst 97497

Pashchenko E N, Dubinskoya P P, Mal'tsev V F and Volkova N P 1974 Zavodsk. Lab 401430

Peng Z and Wu R 1988 Lihua Jianyan. Huarue Fence 24348

Pilipenko A T. Zhebentyaev A I and Voikova A T 1974 Zh. Anal. Khim. 291854

Pyantnitskii I V and Chung D 1969 Zh. Anal. Khim. 24545

Pyantnitskii I V and Chung D 1970 Zh. Anal. Khim. 2591

Quin G 1988 Fenxi Shiyanshi 738

Rajeev 1986 J. Mines Metals and Fuels 411

Rajeev, Srivastava S C and Ghosh M K 1980 NML Tech. J. 2235

Randa Z, Benada J, Kuncir J and Vobecky M 1970 Radiochem. Radioanal. Lett. 3227

Rao P D 1970 At. Absorption New's Letter 9131

Rao P V J, Annaji and Raman D V 1987 Proc of national workshop on tungsten resources detelopment (Bhubaneswar) 3, 6 p. 167

Raoot Sarla, Athavale S V and Rao J H 1986 Analyst 111115

Raoot Sarla. Athavale S V and Subramanian C V 1987 Proc. of national workshop on tungsten resources development (Bhubaneswar) 3, 7 p. 153

Ray Choudhary Alaknanda, Roy S K and Chakraburthy A K 1992 Talanta 391377

Salinas Francisco, Munoz de ta Pena. Arsenio Capitan - Vallvey, Luis F and Navalon Alberto 1989 Analyst 1141297

Sandell E B 1950 Colorimetric determination of traces of metals (Inter Science Publishers Inc.) p. 584

Sen N, Roy N K and Das A K 1989 Talanta 36697

Shinde V M and Khopkar S M 1969 Talanta 16525

Shiralieva S M and Verdizade N A 1984 Azerb. Khim. Zh. 678

Short H G 1951 Analyst 76101

Simon F O and Rollinsov C L 1975 U.S. Geol. Surt. J. Res. 3475

Sinclair A G 1969 Talanta 16459

Smith D P and Pope M T 1968 Anal. Chem. 401906

Srivastava S C, Rajeev and Ghosh M K 1980 J. Mines Metals and Fuels 2822

Srivastava S C and Singh S 1987 Proc. of national workshop on tungsten resources development (Bhubaneswar) p. 129

Sun P 1981 Fenxi Shiyanshi 1026

Tamura N 1974 Radiochem. Radioanal. Lett. 18135

Tang Z, Jin Z, Wang Q and Li G 1991 Guangpuxue Yu Guanypu Fenxi 1133

Thomas P E and Pickering W F 1971 Talanta 18127

Thompson M and Walsh J N 1983 A handbook of inductively coupled plasma spectrometry (London: Blackie) pp. 102, 104

Topping Joseph J 1978 Talanta 2561

Tremendzhyan Z Z and Gaibakyan B S 1974 Arm. Khim. Zh. 2725

Tseryata Yu S, Bagreev V V, Basov A S and Zolotov Yu A 1973 Zh. Anal. Khim. 28946

Wagh D N 1990 Comparison studies on the determination of tungsten using different analytical techniques, M Sc Thesis, Bombay University, Bombay

Weiss J, Moeckel H J, Miller A J, Diemann E and Waeberg H J 1988 J. Chromatogr. 43993

Welsch E P 1983 Talanta 30876

Wenk G J and Wilkinson L. R 1974 AMDEL. Bull 17 I

Wu Jiaqi, Li Bin, Qu Ronggian, Ni Qidao and Zhang Maosen 1985 Fenxi Huaxue 13197

Wunsch W 1979 Talanta 26291

Xia D, Guan X and Huang H C 1991 Yankuang Ceshi 10185

Xin Lili 1983 Yankuany Ceshi 2142

Yatirajam V and Ram J 1973 Microchim. Acta 77

Yoshikuni Nobutaka 1984 Anal. Chim. Acta 156335

Yuan Chengye 1989 Xiyou Jinshu 815

Yunikova N V and Boichinova E S 1984 Zh. Anal. Chim. 3930

Zaitsev E I, Margolin E M, Polytsya O P, Pan'kin V V and Shchekin K I 1974 Zh. Anal. Khim. 29668

Zhen Hai Fan 1992 Anal. Chim. Acta 270267

Zinner H, Henkelmann R and Staerk H 1972 Radiochem. Radioanal. Lett. 10191

Zolotov A Yu, Shpigun O A and Bubchikova I A 1983 Frehnuis Z. Anal. Chim. 3108 